\title{
The Effect of Task-Related Emotional and Cognitive Involvement on Incidental Acquisition of Second Language Vocabulary
}

\author{
Massoud Rahimpour \\ Department of Foreign Languages and Literature, University of Tabriz, Tabriz, Iran \\ School of Languages and Comparative Cultural Studies, University of Queensland, Australia \\ E-mail: Rahimpour2011@gmail.com \\ Parviz Ajideh \\ Department of Foreign Languages and Literature, University of Tabriz, Tabriz, Iran \\ E-mail: parvizaj@gmail.com \\ Davoud Amini (Corresponding author) \\ Department of Foreign Languages and Literature, University of Tabriz, Tabriz, Iran \\ Tel: +989144004080Ｅ-mail: davudamini@Yahoo.com \\ Farahman Farrokhi \\ Department of Foreign Languages and Literature, University of Tabriz, Tabriz, Iran \\ E-mail: ffarrokhi20@yahoo.co.uk
}

Received: 12-12- 2012

Accepted: 29-01- 2013

Published: 01-03- 2013

doi:10.7575/aiac.ijalel.v.2n.2p.193

URL: http://dx.doi.org/10.7575/aiac.ijalel.v.2n.2p.193

\begin{abstract}
Both cognition and affect have been proven to have a significant role in instructed second language acquisition. Unlike cognitive processes, the affective processes in language learning have not received due attention in the research on taskbased language teaching. The effect of task-related emotional state on learning achievements resulting from task engagement is an almost unexplored area. The study reported here investigated the effect of emotional involvement as compared to cognitive involvement both applied to the pre-task phase of a reading-while-listening focused task on lexical acquisition as a result of engagement with the task. Emotional involvement was operationalized as a video clip shown before the main task which elicited positive affect. MANCOVA statistics indicated that both emotional and cognitive involvements had an enhancing effect on short-term retention and ease of activation of vocabulary. However, the enhancing effect was not observed for long-term acquisition. The findings imply pedagogical suggestions for taskbased vocabulary teaching.
\end{abstract}

Keywords: task effectiveness, emotional involvement, cognitive involvement, incidental vocabulary

\section{Introduction}

Learning vocabulary is an incremental process (Schmitt, 2010), and as such, the development of vocabulary for both recognition and production needs, relies on a good number of cognitive processes to perceive, store and retrieve new words. These processes include such phenomena as perception, attention, noticing, memory functioning, appraisal of stimuli, repetition, association and consolidation of lexical knowledge. But none of these cognitive processes takes place in void, detached from affective functioning of learners' mind and body (Dai \& Sternberg, 2004). The interaction that goes on between affective and cognitive processes during such learning activities as the acquisition and processing of new vocabulary and the subsequent upheavals in language performance as a result of this interaction may be regarded as one of the main reasons why a great majority of $\mathbf{L}_{2}$ vocabulary develops through incidental encounters where there is a profitable balance between cognitive, emotional and motivational aspects of intellectual functioning. However, the collective nature of an instructional environment is somehow in conflict with individual learners' wholeperson involvement.

A significant breakthrough in $\mathbf{L}_{2}$ teaching literature to resolve this conflict is task-based curriculum (Skehan, 2003). Task-Based Language Teaching (TBLT) is an attempt to provide an optimally authentic atmosphere to involve learners in a meaningful, goal-oriented interaction with the material, peers, instructor and the world inside themselves. An authentic involvement would incredibly require the beckoning of experiential knowledge as well as emotional and motivational engagement. From that perspective, TBLT does not simply engage learners in authentic cognitive gymnastics such as decision-making and problem-solving. Rather, the emotional involvement exercised by individual learners who are engaged in tasks will claim a massive effect on linguistic achievements from task engagement. 
Despite the critical significance attributed to learners' affective state before, during and after task performance for educational effectiveness of tasks, the affective aspect of task performance has not received the due attention in the TBLT literature (Swain, 2011). Very little is known about how affect influences cognitive processing involved in language learning tasks. Important questions still remain unattended regarding the relationship between cognitiveaffective processes in the learning situation and the effectiveness of the tasks specifically designed to promote incidental acquisition of $\mathrm{L}_{2}$ vocabulary. The study which is reported here was an attempt to investigate the distinctive impacts of emotional and cognitive involvements on task effectiveness and the related language learning outcome in terms of incidental acquisition of $\mathbf{L}_{2}$ vocabulary. The findings of the study can help develop pedagogical techniques to enhance task effectiveness and language learning outcome.

\section{Review of the Related Literature}

\subsection{Incidental Vocabulary Acquisition}

One of the influential positions in offering a breakthrough to the robust task of $\mathbf{L}_{2}$ vocabulary acquisition was the idea of incidental vocabulary acquisition. Although there have been controversies over what is exactly meant by the term 'incidental' (Gass, 1999), the concept seems to have been refined to the following definition: "Incidental learning is the process of learning something without the intention of doing so. It is also learning one thing while intending to learn another." (Brown, Waring \& Donkaewbua, 2008: p. 136) Hulstijn (2003) considers the absence of the preannouncement of a vocabulary test before the task completion as the main indicator of incidental vocabulary learning.

The majority of studies on incidental vocabulary acquisition in a foreign language during 1990s implied picking up formal and semantic aspects of lexicon through context-based extensive reading and listening (e.g. Paribakht \& Wesche, 1999). However, in the last decade, due to the development of focus on form movement and task-based language teaching, vocabulary learning researchers have also begun to advocate focused instruction of vocabulary (de la Fuente, 2006; Laufer, 2005) where input-based tasks are accompanied by a set of enhancement techniques such as dictionary use, frequency control, glossing, etc. One of the instructional techniques for the elaboration of input through reading was glossing (Watanabe, 1997). Different forms of glosses - marginal and multiple choice, $L_{1}$ and $L_{\mathbf{z}}$ - were put into scrutiny. The current study uses within-text translation glosses as the enhancement technique to assist the processing of unfamiliar words within the reading-while-listening text since $L_{1}$ glosses have been proved to be more effective than, or at least as effective as, $\mathbf{I}_{\mathbf{z}}$ glosses in contributing to vocabulary acquisition (Azari, 2012).

\subsection{Task Effectiveness and Cognitive Processes}

The theoretical basis of TBLT lies in two general theories of learning: Socio-cultural theory and cognitive theories. From cognitive perspective, focused tasks facilitate the acquisition of language forms by providing the conditions for cognitive processes involved in perceiving, storing and retrieving the linguistic knowledge (Ellis, 2003). Therefore, from cognitive point of view, the effectiveness of tasks depends to a large extent on the type and quality of mental actions involved in task performance (Moonen, Degraaff \& Westholf, 2006). Effective acquisition of language forms results from the effective processing of the forms in a meaning-focused context. Studies within the cognitive views of TBLT have attributed the effectiveness of cognitive processes in language acquisition to the characteristics and conditions of task performance (Robinson, 2001, 2005; Skehan, 1998, 2003). However, the majority of the research agenda in this regard has focused on the effect of task characteristics and conditions on such performance factors as fluency, accuracy and complexity (see Salimi, Alavinia, Hosseini \& Shafaee, 2012). For instance, Robinson (2001) distinguished between task complexity, task difficulty and task conditions which might lead to different levels of fluency, accuracy and complexity in oral and written performance. Skehan $(1998 ; 2003)$ proposed code complexity, cognitive complexity and communicative stress as the three determining elements of task complexity.

Despite the insight they offer, these models do not explain any association between different types of mental processing induced by tasks and the acquisition of linguistic elements including lexical items. The concept of task-induced involvement proposed by Laufer and Hulstijn (2001) is one of the few postulations to account for the relationship between the mental actions induced by tasks and vocabulary acquisition. Also, in a study of the relationship between task complexity and incidental acquisition of vocabulary, Alavinia, Bonyadi and Malehmir-Chegini (2012) demonstrated that the meaning-focused instruction based on task complexity led to improved vocabulary acquisition and retention.

In addition to task features and conditions, the cognitive load imposed by a task has been considered as a crucial factor affecting task performance. Rahimpour (2010) postulated that "part of the complexity and difficulty of tasks lies with the cognitive load imposed by a task" (p. 192). In the case of vocabulary acquisition through text-based tasks, the cognitive load of a task is typically ascribed to the linguistic and schematic knowledge involved in completing the task. In a series of studies, Pulido examined the individual differences in incidental acquisition of vocabulary through reading. According to Pulido (2003), reading proficiency had a robust effect on recognition and production of incidentally-acquired words both in short-term and long-term acquisition, whereas familiarity with the topic of the text made differences only on recognition performance in short-term testing. Investigating the possible effects of reading ability and background knowledge on lexical inferencing through reading, Pulido (2009) found that a higher level of reading ability and familiarity with the topic led to deeper processing of unknown words in the reading text. This finding was in contrast with Mondria (2003) according to which the effortful process of inferencing does not lead to better retention of unfamiliar words when compared to reading with textual aids such as $\mathrm{L}_{1}$ translations. Examining the 
conduciveness of cognitive involvement of participants during task engagement on incidental acquisition of vocabulary is one focus of this study.

\subsection{The Role of Affect in SLA}

The recognition of the key role played by affective factors in second language acquisition is as old as the field of SLA itself. Such affective variables as anxiety, attitude, self-esteem, personality factors, classroom atmosphere, and teacherlearner relationship have been manifested in language teaching methodology in the history of SLA. Some of these methodologies have dealt with affective concerns in their locus, making a direct association between affective variables and learning. Humanistic methodologies of 1970's, Krashen's affective model, learner centered learning, socio-cultural model, cooperative learning, and experiential learning are among affect-oriented methodologies (Richards \& Rogers, 2001). One of the most conspicuous attempts to integrate affective observations into language teaching practice is what has come to be known as 'Humanistic Language Teaching' (HLT). However, there's not a unified definition of HLT in the literature. While some observers attribute the title to a set of innovative methods of the 1970's such as Community Language Learning, Silent Way and Suggestopaedia (Richards \& Rogers, 2001), others consider it as a general approach encompassing broader visions than that of a particular method (Stevick, 1990). Affective dimensions of learning have a unique position in instructions suggested by HLT. Stevick (1990) as an enthusiastic advocate of HLT identified five emphases within humanistic pedagogy including feelings, social relations, responsibilities, intellect and self-actualization. In addition to HLT-based methodologies of 1970's, almost all of the methodological proposals for language teaching including communicative language teaching and TBLT seem to contain some elements of HLT. TBLT has borrowed a good number of axiomatic beliefs proposed by humanistic education. Emphasis on holistic development of the learner, personal relevance of the subject matter to the learner, imagination and creativity and goaloriented classroom activities are among the many common features of TBLT and HLT.

Another area of integrating affect into language teaching has been the theory of Emotional Intelligence (EI). The emergence of Multiple Intelligences Theory (Gardner, 1983) had its own share in underscoring the indispensible role of affect in language learning. In a thought-provoking article, Arnold and Fonseca (2004) proposed a general framework to apply MIT to the EFL classroom. According to this framework, language learning tasks are developed around different types of intelligences. For example, in a role-play involving expression of feelings while being considerate of others' feelings, at least three types of intelligence, i.e., linguistic, intrapersonal and interpersonal intelligences are evoked. In this MI-based model of the second language teaching each type of intelligence provides a hook through which English can be acquired (Mirzazadeh, 2012). Providing a variety of language activities that evoke different types of intelligences makes multiple memory pathways produce sustained deep learning (Schumann, 1997). Arnold and Fonseca (2004) assert that different aspects of second language acquisition such as reading comprehension and vocabulary recall (Sadoski, Goetz \& Fritz, 1993) are mediated by multiple ways of meaning-making stimulated by different tasks related to different intelligences. This makes up the theoretical suggestion for applying MI theory to TBLT (Zhu, 2011). Central to many of the MI-based proposals for SLA is the affective responses associated with language learning activities that call upon each type of multiple intelligences.

There has been growing interest within cognitive psychology over the past two decades in examining memory for the stimuli that evoke emotional responses. Evidence collected by experimental studies (reviewed by Hamann, 2001; Kensinger \& Schacter, 2008) indicate that emotionally-loaded experiences are remembered better than non-emotional ones. The effect of emotion on memory enhancement has been demonstrated for a variety of emotional stimuli including words, sentences, pictures and videos (Kensinger, 2004). By and large, memory enhancement for emotional data has been taken for granted due to the abundance of experimental focus on this subject (Dolcos, Iordan \& Dolcos, 2011). What remains for scrutiny is the 'how and why' of emotion-memory interactions. According to LaBar and Cabeza, these interactions "occur at various stages of information processing, from the initial encoding and consolidation to their long-term retrieval". (2006: p. 54)

As to the encoding stage of information processing, not all perceptual information can be processed simultaneously due to limited capacity in processing. Therefore, attentional system acts selectively upon relative sensory information (Kensinger, 2004). According to Kensinger (2004), both dimensions of emotion, i.e., arousal and valence modulate selective attention; that is, emotionally arousing or valenced information capture attention. Furthermore, emotionally charged information are prone to 'facilitated or prioritized processing' (p. 243). The result is that emotional stimuli are more likely to receive selective attention compared to non-emotional stimuli.

In addition to its effect on encoding, emotional load of the information being processed has an enhancing effect on consolidation of memory. Memory consolidation is a concept introduced in the early $20^{\text {th }}$ century by Muller and Plizecker (1900) to account for a process by which memories become more resistant to interference. A formal definition describes consolidation as "the progressive post-acquisition and stabilization of long-term memory as well as memory phases during which such presumed stabilization takes place" (Dudai, 2004: p. 52). Consolidation is regarded to be accomplished in two phases: An early phase which lasts about several minutes or hours, and a late phase which may last weeks, months and even years. A major predictor of memory consolidation is the degree of emotional arousal which in turn enhances declarative memory (Cahil \& McGaugh, 1998; LaBar \& Cebeza, 2006; McGaugh, 2000).

Emotional memory can also explain a layperson's experience in learning a second language according to which the words associated with an emotional load take less effort to learn and remember. Laboratory researches have confirmed layman impressions regarding recall advantage for emotional words in second language (Aycicegi \& Harris, 2004; Aycicegi-Dinn \& Caldwell-Harris, 2010; Ferre, Garcia, Fraga, Sanchez-Casas \& Molero, 2010; Jay, Caldwell-Harris \& 
King, 2008). This phenomenon, known as 'emotion-memory effect' (Aycicegi-Dinn \& Harris, 2010) or 'emotionality effect' (Jay, et al., 2008), is observed when participants perform a task on a list of words and are later tested whether for recognition or production of the same words. These studies indicate that emotional words have superiority over neutral words for later recall and retention (Hadley \& MacKay, 2006; Kensinger \& Corkin, 2003; MacKay \& Ahmetzanov, 2005). Kensinger and Corkin (2003) reported an experimental study which supported not only a quantitative memory benefit for emotional words compared to neutral ones, but also qualitative advantage in terms of vividness by which the details related to the presentation of words are remembered.

The recall advantage for emotional words may be modulated by a variety of factors. Among these factors are the valence (positive or negative) and arousal attributed to emotional words. For example, Ferre et al. (2010) found that the emotionality advantage in recall was higher for positive emotional words compared to negative emotional words. Aycicegi-Dinn and Caldwell-Harris (2010) reported that negative words had no recall advantage over neutral words. There are also studies that have conditioned the superior recall of positive-valenced words to the age of participants (Kensinger, 2008). Kensinger (2008) has also argued that differences between memories for positive or negative emotional words could be modulated by their arousal, in a way that highly-arousing words showed no difference in recall rate regardless of their positive or negative valence.

Lately, more and more research studies are highlighting the significance of art, imagination, literature and language play in effective development of second language (e.g. Pomerantz \& Bell, 2007). The fact that imagination, art and literature have the capacity to induce emotional response is well-known to language pedagogists. However, serious endeavors in the realm of both theory and practice to scrutinize the applications of this capacity to SLA are unjustly lacking. In an emotionally poignant article, Luk (2002) wrote about her experience of EFL classes where she utilized a short story titled 'Later' to teach different SL skills including writing, reading, speaking and even grammar. The point raised by Luk is that "this story is only a means to create an 'emotional' atmosphere to make learning more meaningful and memorable" (p. 5).

Underlining the significant role of emotional state in language learner, however, is not meant to undermine the role of cognitive processes. Rather, as Howard Gardner (1983), the innovator of multiple intelligences theory, suggests affect needs to be brought to the foreground. In this study the relative effectiveness of emotional and cognitive involvement in task engagement leading to vocabulary acquisition has been brought into scrutiny.

\subsection{Positive Affect: Broaden and Build Theory}

The role of affective status of a language learner has never been a central issue for the researchers of second language learning and teaching. Among the few affective variables that have received relative attention are stress, anxiety and attitude toward target language and society. A quick review of these studies indicates that they have mainly focused on negative affect. As a matter of fact, studies concerning the role of positive affect in language learning are almost lacking.

Traditionally, distinctive negative emotions have been linked with specific action tendencies (Fredrickson, 2001). For example, fear is associated with the tendency to escape and anger with the tendency to attack. In line with this argument, some researchers have tried to associate distinctive positive emotions with particular action tendencies such as joy being linked to aimless activation and interest with attention (Frijda, 1986). Fredrickson evaluated these associations as vague and proposed instead a general theory to account for the effect of positive emotions on cognitive and behavioral changes which is known as The Broaden and Build Theory (Fredrickson, 1998; 2001).

According to this theory which is associated with positive psychology, negative emotions narrow down momentary actions as a result of instinctive approach-avoidance tendencies. In contrast, positive emotions broaden thought-action repertoires promoting the individual's personal resources including intellectual, social and psychological resources (Fredrickson, 1998, 2001; Fredrickson \& Brinigan, 2005). 'Joy', for example broadens thought-action tendencies by creating the urge to play and 'interest' by creating the urge to explore and take in new information (Fredrickson, 2001). So, positive emotions broaden thought-action repertoires while negative emotions narrow them (see Figure 1).

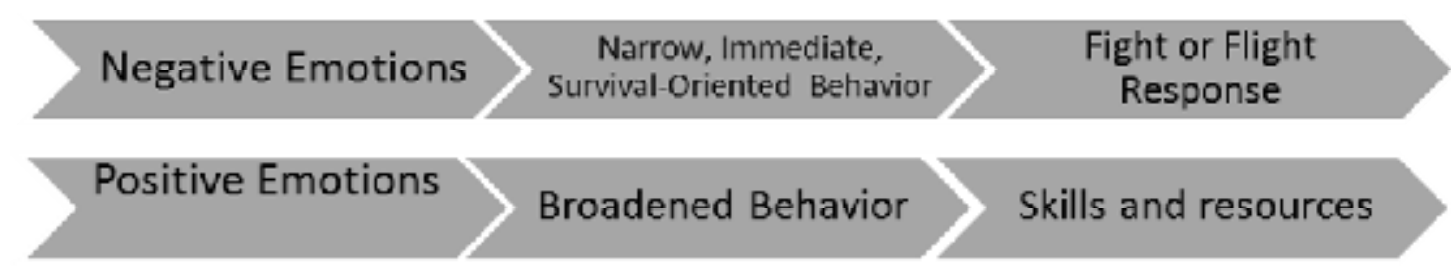

Figure 1. The effect of negative and positive emotions on human activities

Broaden and Build Theory is comprised of two complementary hypotheses: The 'Broaden Hypothesis' states that positive emotions widen action-thought tendencies. Fredrickson and Branigan (2005) were able to demonstrate in laboratory conditions that positive emotions stimulated by short video clips broadened the scope of attention, an important cognitive phenomenon. A good number of empirical studies carried out by Fredrickson and her associates in her positive Emotions and Psychophysiology Lab at the University of Michigan and later at the University of North 
Carolina are corroborative of the broadening effect of positive emotions on such cognitive processes as attention and perception (for a review see Fredrickson, 2003; 2008; 2012).

The second hypothesis within the 'broaden and build theory' is 'The Build Hypothesis' according to which experiencing positive emotions leads to 'resourcefulness and optimal functioning' (Fredrickson, 2012). Fredrickson and coresearchers conducted a set of laboratory researches to verify the claims made by the Build Hypothesis (for a list if publications on this topic, visit www.positiveemotions.org).

Put together, these two hypotheses which have been formulated as the Broaden and Build Theory advocate the observation that positive emotions are involved in broadening the scope of attention, cognition and action as well as building physical, intellectual and social resources in the individual (Fredrickson, 1998). According to Fredrickson (2001), "experiences of positive affect prompt individuals to engage with their environments and partake in activities" (219).

Common techniques employed in the empirical studies to provoke positive emotions in participants are showing video clips or pictures and playing music (Gross \& Levenson, 1995). The present study will use a film clip to provoke positive emotions and provide for emotional involvement.

The review of literature above indicates that the three areas of incidental vocabulary acquisition, task-based language teaching and affect in language learning have been studied mostly in isolation from each other. Very little is known about how incidental vocabulary acquisition can be facilitated in a task-based program, or what effects the affective states of the learners might have on task effectiveness. The relative contributions of cognitive and affective processes involved in task-performance to task effectiveness and incidental learning of vocabulary are not known either. The study reported here is an attempt to bring together the above-mentioned three research areas to examine the relevance of affective and cognitive processes involved in task performance to the learning of linguistic elements as a result of engagement with the task in hand. More specifically this study aimed at investigating the effect of the emotional and cognitive involvement on task effectiveness in incidental acquisition of $\mathbf{L}_{2}$ vocabulary.

\section{Method}

\subsection{Research Questions and Hypotheses}

The following three questions were the main focus of the study:

1. What is the effect of emotional involvement and cognitive involvement applied to the pre-task phase of a reading-while-listening task on short-term retention and ease of activation of second language vocabulary?

2. What is the effect of emotional involvement and cognitive involvement applied to the pre-task phase of a reading-while-listening task on long-term retention and ease of activation of second language vocabulary?

3. In case of effectiveness, is there a difference between emotional and cognitive involvements applied to the pretask phase of a reading-while-listening task in affecting short-term and long-term acquisition of vocabulary?

To initiate the study, the following three hypotheses were proposed:

1. The emotional involvement and cognitive involvement applied to the pre-task phase of a reading-whilelistening task have enhancing effects on short-term retention and ease of activation of second language vocabulary.

2. The emotional involvement and cognitive involvement applied to the pre-task phase of a reading-whilelistening task have enhancing effects on short-term and long-term retention and ease of activation of second language vocabulary.

3. There is a significant difference between the emotional and cognitive involvements in task-engagement in affecting short-term and long-term retention and ease of activation of second language vocabulary.

The independent variable of the study was the type of mental action in task engagement-- emotional involvement and cognitive involvement-- applied to TBLT classroom through pre-task intervention. The dependent variable was incidental acquisition of SL vocabulary resulting from engagement with a reading-while-listening task. The incidental vocabulary acquisition was measured at the level of its four subcomponents:

1. Short-term retention of vocabulary as measured with a test of passive vocabulary immediately after the task engagement

2. Short-term ease of activation of vocabulary as measured with a test of active vocabulary immediately after the task engagement

3. Long-term retention of vocabulary as measured with a test of passive vocabulary two weeks after the task engagement

4. Long-term ease of activation of vocabulary as measured with a test of active vocabulary two weeks after the task engagement

\subsection{Research Context}

In this study, 79 B.A. students of English as a foreign language in Iran were presented three types of pre-task involvement activities prior to their engagement in the main task, glossed reading-while-listening task. They were given active and passive vocabulary tests immediately after the task engagement and two weeks later to assess their acquisition and retention of 20 target words from the reading-while-listening text. 


\subsection{Subjects}

Three intact classes of junior students of English as a foreign language at the Islamic Azad University, Tabriz Branch were randomly selected out of 8 available junior classes for this study. To ensure homogeneity of the three groups, a pretest was administered to the students in three classes, and those who scored below and above the range of 6-25 were left out of the data analysis. Then the three classes were randomly labeled as control group, emotional involvement (EI) group, and cognitive involvement (CI) group including 24(16 female, 8 male) and 26 (15 female, 11 male) and 29 (19 female, 10 male) students, respectively. The subjects aged between 21 and 36).

\subsection{Materials}

The main task was a reading-while-listening task. The text for the reading-while-listening task was extracted from a popular success book Giant Steps, written and read out by Anthony Robins (Robins, 1997). The 20 target words had been signified by $\mathbf{L}_{1}$ glosses within the text. The reading text was followed by a whole-class discussion of the topic of the text The Vocabulary of Success. The students were asked to use as many arguments and illustrations from the text as possible.

The pretest included reading and listening comprehension items taken from archive versions of TOEFL iBT as the overall listening and reading skills were assumed to be relevant to task performance.

The post-tests were comprised of a vocabulary retention test and a vocabulary ease of activation test. The retention test was a test of passive vocabulary including 10 four-item multiple choice word translation questions from English to Persian. In order to neutralize the effect of guessing, a 5th item stating 'I'm not sure' was added to the response options. The ease of activation test included 10 fill-in-the-gap sentence translation items from Persian to English. The English translations of the sentences were provided except for the target words

To elicit positive affect for the emotional involvement group, a humorous movie of about 15 minutes from the English comedy series, My Family was shown in the pre-task phase.

To ascertain the validity of the pre-task video in inducing positive affect for the emotional involvement group, an internationally reliable short form the positive and negative affect schedule (PANAS-SF) developed by Thompson (2007) including selective 10 items measuring positive and negative affect was employed.

\subsection{Procedure}

To choose the target words, 40 words from the reading-while-listening text, conjectured to be less familiar to the students, were selected and then put to a survey from the students two weeks prior to treatment sessions. The survey asked students whether they signified each word as familiar or not. If yes, they were supposed to provide an equivalent or explanation in $\mathrm{L}_{1}$. 20 words which were checked as unfamiliar were selected for the study.

Both control and experimental groups participated in a text-based task preceded by a pre-task phase and succeeded by a post-task phase. The main task was a reading-while-listening task involving reading a text while listening to it read out by the author. The target words had been highlighted using within-text $\mathbf{L}_{1}$ glosses. The post task entailed a whole-class discussion of the information presented by the reading-while-listening text. The discussion was stimulated by a set of triggering questions that summarized the main points in the text.

While the main task and the post task were identical for all three groups, the procedure for the pre-task phase was different for the control group, EI group and CI group. The EI group was shown the humorous video assumed to elicit positive affect following a brief introduction of the movie subject and the task succeeding it. The learners in the CI group first were read out a short text presenting a biography of Anthony Robins, the author of The Giant Steps, and the general theme of his publications. Then a whole-class brainstorming session went on about word power and effective communication in social relations and career success. Amid the brainstorming, some of the non-target words from the reading-while-listening text were written on the board and illustrated by the teacher. The control group was engaged in a different kind of activities for the pre-task phase. They read a passage on effective communication and answered 8 comprehension questions that followed. The pre-task activities took about twenty minutes for each of the three groups.

The two tests for measuring short-term retention and ease of activation of target vocabulary were administered immediately after the task completion. The tests for measuring long-term retention and ease of activation were administered two weeks later.

\section{Data Analysis and Results}

This empirical study was intended to investigate the effect of Emotional Involvement (EI) and Cognitive Involvement (CI) in task performance on four dependent variables, i.e. short-term retention (STR), long-term retention (LTR), shortterm ease of activation (STEA) and long-term ease of activation (LTEA) of $\mathbf{L}_{2}$ vocabulary. The descriptive statistics (means, standard deviations and number of participants) of measures for the four dependent variables are introduced in Table 1.

Table1. Descriptive statistics

\begin{tabular}{|c|c|c|c|c|}
\hline & & $\mathrm{N}$ & Mean & SD \\
\hline \multirow[t]{4}{*}{ Short term retention } & Control & 24 & 2.08 & 1.558 \\
\hline & Emotional Involvement & 26 & 3.54 & 2.044 \\
\hline & Cognitive Involvement & 29 & 3.66 & 1.987 \\
\hline & Total & 79 & 3.14 & 1.992 \\
\hline
\end{tabular}




\begin{tabular}{|c|c|c|c|c|}
\hline \multirow{4}{*}{ Short term ease of activation } & Control & 24 & 1.63 & 1.173 \\
\hline & Emotional Involvement & 26 & 2.73 & 1.538 \\
\hline & Cognitive Involvement & 29 & 2.76 & 1.480 \\
\hline & Total & 79 & 2.41 & 1.489 \\
\hline \multirow[t]{4}{*}{ Long term retention } & Control & 24 & 1.79 & 1.215 \\
\hline & Emotional Involvement & 26 & 2.00 & 1.386 \\
\hline & Cognitive Involvement & 29 & 2.07 & 1.412 \\
\hline & Total & 79 & 1.96 & 1.334 \\
\hline \multirow[t]{4}{*}{ Long-term ease of activation } & Control & 24 & 1.63 & 1.096 \\
\hline & Emotional Involvement & 26 & 1.88 & 1.243 \\
\hline & Cognitive Involvement & 29 & 1.79 & 1.292 \\
\hline & Total & 79 & 1.77 & 1.208 \\
\hline
\end{tabular}

To detect the hypothesized differences between the three groups, a between-groups multivariate analysis of variance with pre-test as covariate (MANCOVA) was conducted using the scores on the four dependent measures. Preliminary assumption-testing was conducted to check for normality, linearity and homogeneity of variance-covariance matrices with no serious violations noted. The MANCOVA results demonstrated an overall significant difference between the three groups on the combined dependent variables. Wilks' Lambda was significant at .000 . Tests of between subjects effects indicated significant differences between the three groups on STR $(\mathrm{F}=19.84)$ and STEA $(\mathrm{F}=12.57)$ but nonsignificant difference between them on LTR $(\mathrm{F}=1.6)$ and LTEA $(\mathrm{F}=.84)$. These analyses indicated a statistically significant difference between the control group and the two experimental groups in terms of STR and STEA. However, the differences for LTR and LTEA scores were not different for the two pre-task involvement types and the control.

Follow up analyses for multiple comparisons of involvement type groups separately for each dependent variable indicated significant differences between the control group on the one hand and EI and CI groups on the other. However EI and CI groups were not different on their STR and STEA scores. On the other hand, between-groups analyses for LTR and LTEA scores indicated no significant difference between any pairs of groups. The results of pair-wise analyses of the three groups are presented in figure2.

The results of data analysis confirmed that emotional and cognitive involvement elicited through pre-task intervention had enhancing effects on STR and STEA. But this enhancing effect was not observed for LTR and LTEA. In fact, EI and $\mathrm{CI}$ improved both retention and ease of activation scores in the immediate post-test whereas it did not have any significant effect on the performance upon the delayed post-tests. Therefore, Hypothesis 1 was accepted whereas Hypothesis 2 which predicted an enhancing effect for emotional and cognitive involvement on long-term retention and ease of activation of vocabulary was rejected. Since no significant difference was indicated between the two experimental groups, Hypothesis 3 which predicted different effects for emotional and cognitive involvements in task engagement on incidental acquisition of vocabulary was also rejected.
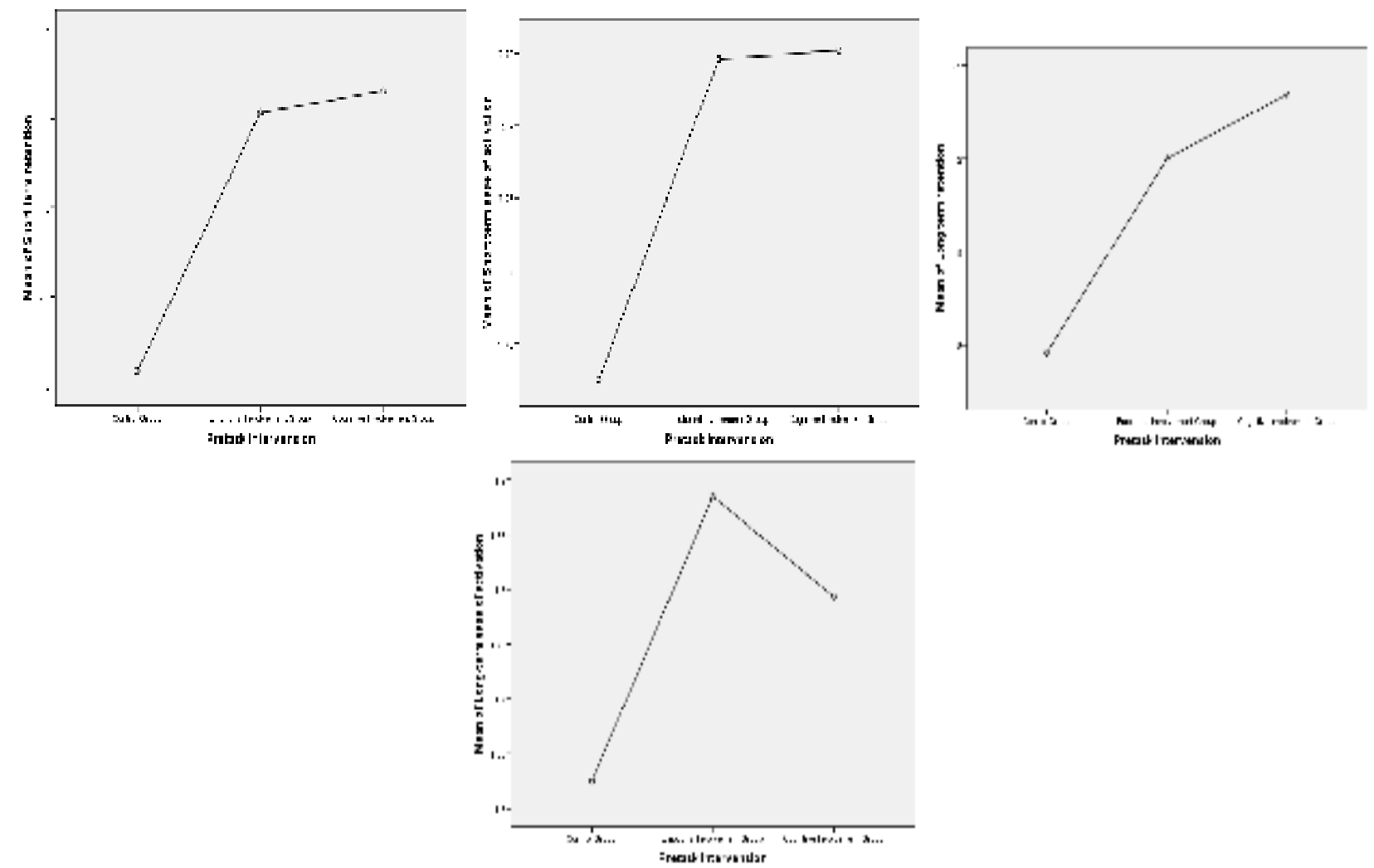

Figure 2. Between-group differences for short-term and long-term retention and ease of activation scores 


\section{Discussion}

This quasi-experimental study intended to examine the differential roles of emotional and cognitive involvements as applied to the pre-task phase of a text-based and input-enhancing task in facilitating the incidental acquisition of unfamiliar vocabulary. The results manifested an enhancing effect for both CI and EI in term of short-term retention and ease of activation. However, the two types of pre-task activities were not significantly different from each other in their enhancing effect.

The conduciveness of cognitive involvement in task performance has been well-recognized by information-processing theories (McLaughlin \& Heredia, 1996). According to these theories, attentional resources of learners in processing newly-encountered information are limited in capacity. Therefore, the cognitive processes of perceiving and storing the details provided in the input are facilitated when the cognitive load imposed by the task demand is lowered (Rahimpour, 2010). Activating some of the linguistic and schematic knowledge required to fulfill the purpose of the reading-whilelistening task proved effective in decreasing the cognitive load of the task setting the attentional resources free to be focused on aspects of lexical knowledge related to the target words introduced through reading-while-listening task. Thus, the input-enhancement technique of glossing appeared effective when it was accompanied by the pre-task intervention to reduce the cognitive demands of the task. The same glosses did not prove effective for the control group where the cognitive pre-task intervention was absent.

The type of pre-task intervention for the second experimental group concerned showing a humorous movie intended to arouse positive affect in the learners before getting engaged in a reading-while-listening task. The emotional involvement through pre-task intervention turned out to have an enhancing effect on short-term retention and ease of activation of target words. This finding is in line with Fredrickson's Broaden and Build Theory, according to which the experience of positive affect encourages the individuals to involve more and more in what is going on in the environment (Fredrickson, 2001). Involving learners in positive affect experience through pre-task activities promoted the learners' engagement with the subsequent learning situation rendering learners capable to make an optimal use of their social and cognitive resources in attending to the input provided by the main task. The relation between affective response to the input and cognitive processes involved has formally been suggested by Stimulus Appraisal Theory (Schumann, 1998). According to Schumann, affective appraisal of stimuli is at the core of cognitive processes from which our behavioral responses are derived (Garret \& Young, 2009). Therefore, affective variables must not be seen as fixed factors in relation to the learning situation. Affect regulation must be regarded as an important element in task design and implementation. Through some case studies focusing on self-regulation of affect in SLA by learners studying Russian as a second language, Bown and White (2010) demonstrated that affect regulation is an integral part of successful learning:

Importantly this finding runs counter to a view of students as having particular, fixed emotional characteristics and reveals instead how emotions arise in relation to particular tasks, settings and learning opportunities and are mediated by cognitive appraisals of those antecedents. (p. 440)

Emotional state of learners in relation to the new word in the input and the text in which they appear will immensely affect the acquisition and recall of those words. Discussing the contributive relevance of Multiple Intelligences theory to EFL, Arnold and Fonseca (2004) suggest that 'language learning tasks be developed around different types of intelligences' (p.126). Among these intelligences is the visual-spatial intelligence which is involved in creating mental images of concepts. According to Arnold and Fonseca (2004), emotional responses are related to our nonverbal processing system which is in close association with the cognitive process of imagery. They assert that "the connection of words with experience and with emotional responses gives words their meaning" (p.127) and hence is a good predictor of words' comprehension and recall.

Accordingly, it is suggested here that input-enhancement techniques such as glossing -as suggested by focused taskscannot in themselves promote the chances of vocabulary acquisition. Rather, it is the inclusion of cognitive and emotional processes induced by task conditions that determines successful retention and recall of vocabulary.

Despite the enhancing effect of both emotional and cognitive pre-task interventions on short-term measures of incidental vocabulary acquisition, there was no indication of an identical effect on long-term measures. The implication is that engaging learners with the input-enhancing task whether emotionally or cognitively was effective in improving the learners' intake of focused items. Nevertheless, a remarkable portion of this learning was subject to a high rate of decay so that ultimately, the active and passive knowledge of vocabulary demonstrated by the emotional and cognitive involvement groups upon the delayed post-tests did not show any significant difference with those who were not provided with either emotional or cognitive interventions. This finding is corroborative of the integrated views of intellectual functioning which see cognitive and affective processes of mind interactively reinforcing each other (Duncan \& Barrett, 2007). Ackerman and Lohman (2006) decline the idea of artificially demarcating affective variables from cognitive processes and emphasize, instead, the fruitfulness of studying the complicated interaction that may possibly take place between these aspects of mind. Furthermore, recent findings in neuroscientific studies of learningrelated brain structures advocate the interactive functioning of cognition and emotion (e.g., Dolcos, Iordan \& Dolcos, 2011).

\section{Conclusion}

As alluded by Swain (2011), cognitive and emotional processes are the two determining variables in the process of second language learning. Meanwhile, there is an interactive functioning of the two elements in facilitating language 
learning. Overemphasizing the cognitive processes over the emotional ones or the converse in instructional situations appears to be counterproductive in leading to more effective learning. Cognitive and emotional interventions in language learning activities are most conducive when there is the chance of interaction between these two aspects of intellectual functioning. Further investigation is required on the nature of mutual reinforcement resulting from the interaction between cognitive and emotional processes in SLA. Moreover, the study reported here examined the effect of a single instructional intervention on the development of linguistic knowledge. Longitudinal studies focusing on the interaction between cognitive and affective processes can open a new perspective in the methodology of second language teaching.

\section{Acknowledgement}

The study reported here is part of a more general Ph.D. project sponsored by the Department of English at the University of Tabriz.

\section{References}

Ackerman, P. L. \& Lohman, D. R. (2006). Individual differences in cognitive functions. In P. A. Alexander \& P. H. Winne (Eds.), Handbook of educational psychology (pp. 139-161). Mahwah, N.J.: Erlbaum.

Alavinia, P. Bonyadi, A. \& Malemir-Chegini, F. (2012). On the effect of task-complexity-based instruction of incidental vocabulary on Iranian academic learners' vocabulary learning. International Journal of Applied Linguistics and English Literature, 1(6), 26-36.

Arnold, J. \& Fonseca, M. C. (2004). Multiple intelligence theory and foreign language learning: A brain-based perspective. International Journal of English Studies, 4(1), 119-136.

Aycicegi, A. \& Harris, C. L. (2004). Bilinguals' recall and recognition of emotion words. Cognition and Emotion, 18, 977-987.

Aycicegi-Dinn, A., \& Caldwell-Harris, C. L. (2009). Emotion memory effects in bilingual speakers: A levels-ofprocessing approach. Bilingualism: Language and Cognition, 12, 291-303.

Azari, F. (2012). Review of effects of textual glosses on incidental vocabulary learning. International Journal of Innovative Ideas, 12(2), 13-24.

Bown, J. \& White, C. J. (2010). Affect in self-regulatory framework for language learning. System, 38(3), $432-443$.

Brown, R., Waring, R. \& Donkaewbua, S. (2008). Incidental vocabulary acquisition from reading, reading-while listening, and listening to stories. Reading in a Foreign Language. 20(2), 136-163.

Cahill L. \& McGaugh, J. L. (1998). Mechanisms of emotional arousal and lasting declarative memory. Trends in Neuroscience, 21, 294-99.

Dai, D. Y. \& Sternberg, R. J. (2004). Beyond cognitivism: Toward an integrated understanding of intellectual functioning and development. In D. Y. Dai and R. J. Sternberg (Eds).Motivation, emotion, and cognition; integrative perspectives on intellectual functioning and development (pp. 3-38). Mahwah, New Jersey: Lawrence Erlbaum Associates, Inc.

Dolcos, F. Iordan, A. D. \& Dolcos, S. (2011). Neural correlates of emotion-cognition interactions: A review of evidence from brain imaging investigations. Journal of Cognitive Psychology, 23(6), 669-694.

Dudai, Y. (2004). The neurobiology of consolidations, or how stable is the engram? Annual Review in Psychology, 55, 51-86.

Duncan, S. \& Barrett, L. F. (2007). Affect is a form of cognition: A neurobiological analysis. Cognition and Emotion, 21(6), 1184-1211.

Ellis, R. (2003). Task-based language learning and teaching. Oxford: OUP.

Ferre', P., Garcia, T., Fraga, I., Sanchez-Casas, R. \& Molero, M. (2010). Memory for emotional words in bilinguals: Do words have the same emotional intensity in the first and in the second language? Cognition and Emotion, 24(5), 760785 .

Fredrickson, B. L. (1998). What good are positive emotions? Review of General Psychology, 2(3), 300-319.

Fredrickson, B. L. (2001). The role of positive emotions in positive psychology: The broaden and build theory of positive emotions. American Psychologist, 56(3), 218-226.

Fredrickson, B. L. (2003). The value of positive emotions. American Scientist, 91, 330-335.

Fredrickson, B. L. (2008). Promoting Positive Affect. In M. Eid and R. J. Larsen (Eds). The Science of Subjective WellBeing (pp. 449-468). NY: Guilford Press.

Fredrickson, B. L. (2012). Positive emotions broaden and build. In E. Ashby Plant \& P.G. Devine (Eds.), Advances on Experimental Social Psychology, Vol. 47 (pp.1-86). Elsevier Inc. 
Fredrickson, B. L., \& Branigan, C. (2005). Positive emotions broaden the scope of attention and thought-action repertoires. Cognition \& Emotion, 19(3), 313-332.

Fredrickson, B. L., \& Cohn, M. A. (2008). Positive emotions. In M. Lewis, J. Haviland-Jones, and L. F. Barrett (Eds).Handbook of Emotions, 3rd Edition (pp. 777-796). New York: Guilford Press.

Frijda, N.H. (1986). The emotions. Cambridge, UK: Cambridge University Press.

de la Fuente, M. J. (2006). Classroom L2 vocabulary acquisition: Investigating the role of pedagogical tasks and formfocused instruction. Language Teaching Research, 10(3), 263-295.

Gardner, H. (1983). Frames of mind: The theory of multiple intelligences. New York: Basic Books.

Garrett, P. \& Young, R. F. (2009). Theorizing affect in foreign language learning: An analysis of one learner's responses to a communicative Portuguese course. The Modern Language Journal, 93(2), 209-226.

Gass, S. (1999). Discussion: Incidental vocabulary learning. Studies in Second Language Acquisition, 21, 319-333.

Gross, J. \& Levenson, R. (1995). Emotion elicitation using films. Cognition and Emotion, 9(1), 87-108.

Hadley, C. \& MacKay, D. (2006). Does emotion help or hinder immediate memory? Arousal versus priority-binding mechanisms. Journal of Experimental Psychology: Learning, Memory and Cognition, 32(1), 79-88.

Hamann, S. (2001). Cognitive and neural mechanisms of emotional memory. Trends in Cognitive Science, 5, 394-400.

Hulstijn, J. H. (2003). Incidental and intentional learning. In: C. J. Doughty and M. H. Long (Eds). The handbook of second language acquisition (pp. 349-381).Malden, MA: Blackwell.

Jay, T., Caldwell-Harris, C. \& King, K. (2008). Recalling taboo and non-taboo words. American Journal of Psychology, 121(1), 83-103.

Kensinger, E. \&Schacter, D. L. (2008). Memory and emotion. In M. Lewis, J. M. Haviland-Jones and L. F. Barrett(Eds). Handbook of emotions (pp. 601-617). New York: The Guilford Press.

Kensinger, E. A. (2008). Age differences in memory for arousing and nonarousing emotional words. Journal of Gerontology, 63B, 13 18.

Kensinger, E.A. \& Corkin, S. (2003). Memory enhancement for emotional words: Are emotional words more vividly remembered than neutral words? Memory and Cognition, 31, 1169-1180.

Kensinger, E.A. (2004). Remembering emotional experiences: The contribution of valence and arousal. Reviews in the Neurosciences, 15, 241-252.

LaBar, K. S., \& Cabeza, R. (2006). Cognitive neuroscience of emotional memory. Nature Reviews Neuroscience, 7(1), 54-64.

Laufer, B. \& Hulstijn, J. (2001). Incidental vocabulary acquisition in a second language: the construct of task-induced involvement. Applied Linguistics, 22 (1), 1-26.

Laufer, B. (2005). Focus on form in second language vocabulary learning. EUROSLA Yearbook, 5, 223-250.

Luk, N. (2002). The role of emotions in language teaching. The Journal of the Imagination in Language Learning and Teaching, VII. Retrieved October 5, 2011 from www.njcu.edu/cill/ vol7/ luk.html.

MacKay, D. G., \& Ahmetzanov, M. V. (2005). Emotion, memory, and attention in the taboo stroop paradigm: An experimental analog of flashbulb memories. Psychological Science, 16, 25-32.

McGaugh, J. L. (2000). Memory--a century of consolidation. Science, 287, 248-251.

McLaughlin, B. \& Heredia, R. (1996). Information-processing approaches to research on second language acquisition and use. In W. C. Ritchie and T. K. Bhatia (Eds), Handbook of second language acquisition (pp. 213-228). San Diego: Academy Press.

Mirzazadeh, M. (2012). Impacts of multiple intelligences on learning English in the ESL classroom. American Journal of Scientific Research, 60, 64-74.

Mondria , J . ( 2003). The effects of inferring, verifying, and memorizing on the retention of L2 word meanings: An experimental comparison of the "meaning-inferred method" and the "meaning given method." Studies in Second Language Acquisition , 25, 473- 499.

Moonen, M. de Graaff, R. \& Westholf, G. (2006). Focused tasks, mental actions and second language learning. Cognitive and connectionist accounts of task effectiveness. International Journal of Applied Linguistics, 152, 35-53.

Müller G. E. \& Pilzecker A. (1900). Experimentelle Beiträge zur Lehre vom Gedächtnis. Z. Psychol. Ergänzungsband $1,1-300$.

Pomerantz, A. \& Bell, N. D. (2007). Learning to play, playing to learn: FL learners as multicompetent language users. Applied Linguistics, 28 (4), 556-578.

Pulido, D. (2003). Modeling the role of second language proficiency and topic familiarity in second language incidental vocabulary acquisition through reading. Language Learning, 53, $233-284$. 
Pulido, D. (2009). How involved are American L2 learners of Spanish in lexical input processing tasks during reading? Studies in Second Language Acquisition. 31, 31-58.

Rahimpour, M. (2010). Cognitive development and language acquisition. In L. Sclia-Cabral (Ed.). Psycholinguistics: Scientific and technological Challenges (pp. 189-194). Port Alegre: ediPUCRS.

Richards, J. C. \& Rogers, T. S. (2001). Approaches and methods in language teaching (2nd ed.). Cambridge: CUP.

Robins, A. (1997). Giant Steps: Small changes to make a big difference. London: Simon and Schuster Ltd.

Robinson, P. (2001). Task complexity, cognitive resources, and syllabus design: A triadic framework for examining task influences on SLA. In P. Robinson (Ed.), Cognition and second language instruction (pp. 287-318). Cambridge: Cambridge University Press.

Robinson, P. (2005). Cognitive complexity and task sequencing: Studies in a componential framework for second language task design. International Review of Applied Linguistics, 43(1), 1-32.

Sadoski, M, E. Goetz \& J. Fritz (1993). Concreteness effects in text recall: Dual coding or context availability? Reading Research Quarterly, 30, 278-288.

Salimi, A. Alavinia, P. Hosseini, P. \& Shafaei, A. (2012). The impact of task complexity and strategic planning time on EFL Learners' accuracy and fluency in written task production. International Journal of Applied Linguistics and English Literature, 1(7), 104-116.

Schumann, J. H. (1997). The neurobiology of affect in language. Malden, MA: Blackwell Publishers.

Schmitt, N. (2010). Researching vocabulary; a vocabulary research manual. London: Palgrave MacMillan.

Skehan, P. (1998). A cognitive approach to language learning. Oxford: Oxford University Press.

Skehan, P. (2003). Task-based instruction. Language Teaching, 36, 1-14.

Stevick, E.W. (1990). Humanism in language teaching. Oxford :OUP.

Swain, M. (2011). The inseparability of cognition and emotion in second language learning. Language Teaching, 45(4), 1-13. doi:10.1017/S0261444811000486.

Thompson, E. (2007). Development and validation of an internationally reliable short form of the positive and negative affect schedule (PANAS). Journal of Cross-Cultural Psychology, 38(2), 227-242.

Watanabe, Y. (1997). Input, intake, and retention: Effects of increased processing on incidental learning of foreign language vocabulary. Studies in Second Language Acquisition, 19, 287-307.

Zhu, H. (2011). The Application of multiple intelligences theory in task-based language teaching. Theory and Practice in Language Studies, 1(4), 408-412. 